\title{
BMJ Open Are patients with stage III non-small cell lung cancer treated with chemoradiotherapy at risk for cardiac events? Results from a retrospective cohort study
}

\author{
Juliette Degens (10 , ${ }^{1}$ D De Ruysscher, ${ }^{2}$ Ruud Houben, ${ }^{3}$ Bastiaan Kietselaer, ${ }^{4}$ \\ Gerben Bootsma, ${ }^{5}$ Lizza Hendriks, ${ }^{6}$ Ellen Huijbers, ${ }^{7}$ Annemie Schols, ${ }^{8}$ \\ Anne-Marie C Dingemans ${ }^{9,10}$
}

To cite: Degens J, De Ruysscher D, Houben $\mathrm{R}$, et al. Are patients with stage III non-small cell lung cancer treated with chemoradiotherapy at risk for cardiac events? Results from a retrospective cohort study. BMJ Open 2020;10:e036492. doi:10.1136/ bmjopen-2019-036492

- Prepublication history for this paper is available online. To view these files, please visit the journal online (http://dx.doi. org/10.1136/bmjopen-2019036492).

Received 17 December 2019 Revised 13 August 2020 Accepted 18 August 2020

Check for updates

(C) Author(s) (or their employer(s)) 2020. Re-use permitted under CC BY-NC. No commercial re-use. See rights and permissions. Published by BMJ.

For numbered affiliations see end of article.

Correspondence to Dr Juliette Degens; juliette.degens@mumc.nl

\section{ABSTRACT}

Objectives Dyspnoea is one of the symptoms frequently encountered after treatment with chemoradiotherapy (CRT) in stage III non-small cell lung cancer (NSCLC). Long-term data on mild to moderately severe cardiac events as underlying cause of dyspnoea in patients with stage III NSCLC are lacking. Therefore, the incidence of new cardiac events, with a common terminology criteria for adverse events (CTCAE) score of $\geq 2$ within 5 years after diagnosis, were analysed.

Design Retrospective multicentre cohort study of patients with stage III NSCLC treated with CRT from 2006 to 2013. The medical files of the treated patients were reviewed. Outcome measures The primary endpoint of the study was the incidence of new cardiac events with a CTCAE score of $\geq 2$ within 5 years after diagnosis. Secondary endpoint was to identify risk factors associated with the development of a cardiac event.

Results Four hundred and sixty patients were included in the study. Of all patients, 150 (32.6\%) developed a new cardiac event. In patients with a known cardiac history $(n=138), 44.2 \%$ developed an event. The most common cardiac events were arrhythmia (14.6\%), heart failure (7.6\%) and symptomatic coronary artery disease $(6.8 \%)$. Pre-existent cardiac comorbidity (HR 1.96; $p<0.01)$ and WH0-performance score $\geq 2$ (HR 2.71; $p<0.01$ ) were significantly associated with developing a cardiac event. The majority of patients did not have pre-existent cardiac comorbidity ( $n=322)$. Elevated WHO/International Society of Hypertension score was not identified as a significant predictor for cardiac events.

Conclusion One-third of patients with stage III NSCLC treated in daily clinical practice develop a new cardiac event within 5 years after CRT. All physicians confronted with patients with NSCLC should take cardiac comorbidity as a serious possible explanation for dyspnoea after treatment with CRT.

\section{INTRODUCTION}

Lung cancer is, next to breast cancer, the most common cancer worldwide contributing

\section{Strengths and limitations of this study}

L Large, multicentre, well-defined group of patients with stage III non-small cell lung cancer treated according to standard clinical care.

- All patients' records have been systematically reviewed based on a predetermined strategy.

- Because of the retrospective analysis we cannot rule out that some cardiac events with common terminology criteria for adverse events score $\geq 2$ were missed.

- Detailed analysis of dose-volume parameters of radiotherapy were not included in this study.

$12.3 \%$ of the total number of new cases diagnosed. ${ }^{12}$ Non-small cell lung cancer (NSCLC) is the most frequently diagnosed form of lung cancer and approximately one-third of all patients with NSCLC present with locally advanced, stage III, disease. ${ }^{3}$ Concurrent chemoradiotherapy (cCRT) is the preferred treatment with a 5-year overall survival (OS) of $25 \%-35 \% .^{4-7}$ Current treatment methods, including CRT with immune modulating therapy such as durvalumab has improved 3-year survival up to $66 \% .{ }^{89}$ As survival rates are improving, long-term adverse events and their potential impact on quality of life become more important. ${ }^{810}$

After completing lung cancer treatment, patients with stage III NSCLC are monitored at the outpatient's clinic every 3 months in the first 2 years and every 6 months in year 3 to $5 .^{11}$ In between these consults, patients commonly visit their general practitioner (GP) with physical complaints possibly related to their treatment. Dyspnoea is one of the problems frequently encountered and can be attributed to radiation-induced pneumonitis 
or an underlying other primary pulmonary problem such as chronic obstructive pulmonary disease. Importantly, recent studies have shown that short-term cardiac events in NSCLC are common. ${ }^{12-15}$ Within 24 months after treatment, the reported incidence of serious cardiac adverse events was $11 \%-23 \%$ in a pooled analysis of prospective dose-escalated radiotherapy trials, where the given radiation dose was higher compared with standard care to improve treatment tolerability or maximise treatment effects. ${ }^{12-14}$ This high incidence of cardiac events was confirmed in a cohort of stage II and III NSCLC $(n=748)$ treated in daily clinical practice showing a cumulative incidence of cardiac events of $23 \% .{ }^{15}$ In these studies, high mean radiation dose to the heart was associated with an increased risk for development of a serious cardiac event. Long-term data on mild to moderately severe cardiac events in patients with stage III NSCLC, who are often first presented to the GP, are still lacking. Therefore, the primary objective of the current study was to analyse the 5-year cumulative incidence of cardiac events with a mild to severe impact in patients with stage III NSCLC, treated with CRT in daily clinical care. The secondary objective was to identify clinical risk factors for the development of a cardiac event in this specific patient cohort.

\section{METHOD}

\section{Study design and study subjects}

This is a retrospective multicentre cohort study of patients with stage III NSCLC treated with cCRT or sequential CRT (sCRT). From 2006 to 2013, all consecutive patients with NSCLC referred from three different hospitals to MAASTRO clinic for radiotherapy, were included in a prospective cohort. In retrospect, patients with pathologically proven stage III NSCLC were selected from this cohort for the current study. A retrospective evaluation of treatment and follow-up was performed. This study was approved by the internal review board of MAASTRO clinic.

\section{Patient and public involvement}

Patients and members of the public were not involved in the design and conduction of this retrospective study.

\section{Patient file search}

A trained physician examined the patient files according to a predetermined case report form (CRF). This CRF was compiled by a research team of pulmonologists, cardiologist and radiation oncologist all working in one of the three hospitals. The following domains of the patient file were reviewed:

\section{General medical history}

Comorbidity expressed as the Charlson comorbidity index (CCI) which predicts the 10-year mortality based on comorbid conditions, use of medication, WHOperformance score (WHO-PS) at diagnosis.
Tumour and treatment-specific information

Date of diagnosis of stage III NSCLC, histological type, recurrence or progression of diagnosed stage III disease and chemotherapy treatment.

Cardiac risk profile based on age, gender, blood pressure, smoking and diabetes status

For each patient the baseline WHO/International Society of Hypertension (WHO/ISH) score for predicting the 10-year risk of a fatal or non-fatal major cardiovascular event (myocardial infarction or stroke) were documented according to age, gender, blood pressure, smoking history and diabetes status.

\section{Pre-existing cardiac comorbidity}

Pre-existent treatment of arrhythmia, coronary artery disease, pericardial disease, heart failure or cardiomyopathy not otherwise specified (NOS).

\section{Development of cardiac events within 5 years after the diagnosis} NSCLC

All cardiac events developed within 5 years after the diagnosis of NSCLC were documented. Both pre-existent and new cardiac events were classified according to common terminology criteria for adverse events (CTCAE score, V.4.0). A cardiac event was included in the analysis if there was (sub)acute need for medical intervention, which corresponds to a CTCAE $\geq 2$. In case of more than one cardiac event, the event with the most impact on morbidity (highest CTCAE score) was included.

The research team defined five different cardiac events: 1. Arrhythmia: symptomatic atrial or ventricular arrhythmia requiring medical or procedural intervention.

2. Coronary artery disease: chest pain with increased cardiac biomarkers, abnormal ECG or proven significant stenosis on cardiac catheterisation followed by intervention.

3. Pericardial disease: containing both the occurrence of pericarditis or non-malignant pericardial effusion confirmed by echocardiography or ECG.

4. Heart failure: shortness of breath due to acute or chronic heart failure (including valve dysfunction) diagnosed by echocardiography or increased cardiac blood parameters.

5. Cardiomyopathy NOS: cardiac resuscitation and cardiomyopathy NOS.

\section{Treatment of NSCLC}

All patients were treated with CRT. Chemotherapy treatment consisted of platinum-based therapy with gemcitabine, etoposide or vinorelbine combined with radiotherapy according to the treatment guidelines in the period 2006-2013 in the Netherlands. The median prescribed dose of radiotherapy was $60-65$ Gy delivered in 30 fractions of $1.5 \mathrm{~Gy}$ in two fractions per day, followed by one fraction a day of $2 \mathrm{~Gy}$ for 2 weeks until organ tolerance was reached. All patients with stage III NSCLC were treated with intensity-modulated radiation therapy (IMRT) from 2009 onwards. In that period, the pursued 


\section{4 stage III NSCLC reffered to MAASTRO for treatment}

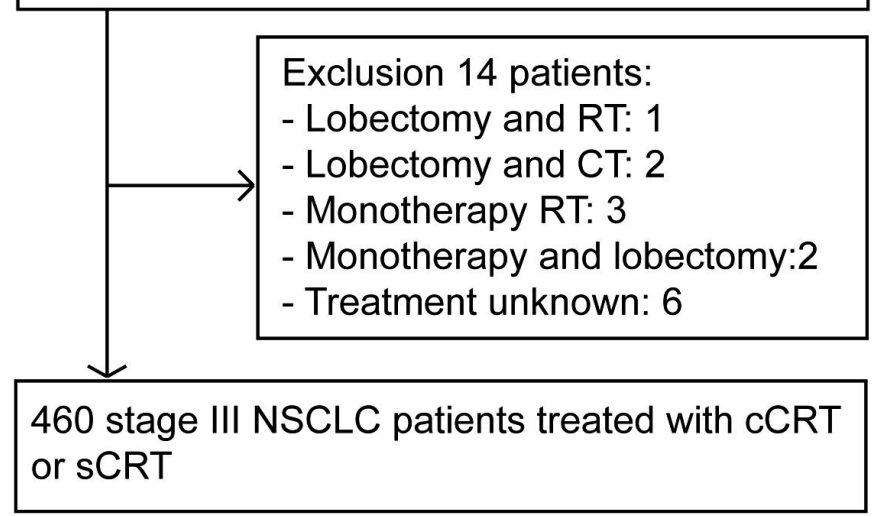

Figure 1 CONSORT diagram $(n=460)$. CRT, chemoradiotherapy; cCRT, concurrent chemoradiotherapy CONSORT, Consolidated Standards of Reporting Trials; NSCLC, non-small cell lung cancer; RT, radiotherapy; sCRT, sequential CRT.

dose-volume constraints for the heart was a mean heart dose of $<45 \mathrm{~Gy}$, reflecting the prevailing opinion that cardiac side effects were not that important in this population for they were presumed to occur after many decades, analogous to patients with Hodgkin's disease. ${ }^{16}$

\section{Statistics}

Descriptive statistics of demographic and clinical variables were obtained. Competing risk analysis was used to analyse the cumulative incidence of all CTCAE $\geq 2$ cardiac events corrected for the competing risk of death. To assess the contribution of different clinical factors to the development of a cardiac event, cox regression analysis was performed by including potential contributing factors in the multivariate analysis, identified as factors yielding a $\mathrm{p}$ value $<0.30$ in univariate analysis. Results with two-sided exact $p$ values $(\leq 0.05)$ were considered statistically significant. A proportional hazard model for the competing risk analysis was performed using R software. All other analyses were performed using SPSS statistical software, V.24.0.

\section{RESULTS}

\section{Patient characteristics}

Four hundred and sixty patients were included in the study (figure 1). Baseline patient characteristics are shown in table 1 .

\section{Cardiac events}

Within 5years after treatment, 150 (32.6\%) patients developed cardiac event (CTCAE $\geq 2$ ). The following cardiac events were observed: arrhythmia $(n=68,14.7 \%)$, symptomatic coronary artery disease $(n=30,6.5 \%)$, heart failure $(n=33,7.2 \%)$, symptomatic pericardial disease $(\mathrm{n}=13,2.8 \%)$ and six $(1.3 \%)$ patients were brought into the emergency room because of cardiomyopathy NOS
Table 1 Patient characteristics $(n=460)$

\begin{tabular}{lll}
\hline & N & $\%$ \\
\hline Male gender & 274 & 59.6 \\
\hline Age (mean, range) & 65.2 & $(32-88)$ \\
\hline WHO-PS* & & \\
\hline 0 & 290 & 63 \\
\hline 1 & 135 & 29.3 \\
\hline$\geq 2$ & 35 & 7.6 \\
\hline Comorbidity index† & & \\
\hline Low (0-3) & 155 & 33.7 \\
\hline Intermediate (4-6) & 234 & 50.9 \\
\hline High (7-9) & 71 & 15.4 \\
\hline WHO/ISH risk scoreł & & \\
\hline Low (<10\%) & 227 & 49.3 \\
\hline High (>10\%) & 177 & 38.5 \\
\hline Unknown & 56 & 12.2 \\
\hline Treatmentł & & \\
\hline cCRT & 391 & 85 \\
\hline sCRT & 69 & 15 \\
\hline
\end{tabular}

Radiotherapy§

\begin{tabular}{lll} 
3D-CRT & 67 & 14.6 \\
IMRT & 393 & 85.4 \\
Chemotherapy & & \\
Combined cisplatine & 311 & 67.6 \\
Combined carboplatine & 127 & 27.6 \\
\hline Otherwise/unknown & 22 & 4.8 \\
Cardiac risk profile & & \\
Smoker (active/former) & $185 / 200$ & $40.2 / 43.5$ \\
Hypertension, yes & 124 & 27 \\
\hline Diabetes mellitus, yes & 66 & 14.3 \\
Statin use, yes & 118 & 25.7 \\
Pre-existing cardiac comorbidity & 138 & 30 \\
Arrhythmia & 37 & 8 \\
\hline Symptomatic coronary artery disease & 61 & 13.3 \\
\hline Pericardial disease & 6 & 1.3 \\
\hline Heart failure & 21 & 4.6 \\
Cardiomyopathy NOS§ & 13 & 2.8 \\
\hline
\end{tabular}

*WHO-PS: quantifies general well-being and activities of daily life of patients with cancer.

†CCI: prediction of the 10-year survival in patients with multiple comorbidities.

¥WHO/ISH risk prediction score: indicates 10 -year risk of a fatal or non-fatal major cardiovascular event according to age, sex, blood pressure, smoking status and diabetes mellitus status.

$\S$ Cardiomyopathy NOS: cardiac resuscitation and cardiomyopathy NOS. $\mathrm{CCl}$, Charlson comorbidity index; CCRT, concurrent chemoradiotherapy; 3D-CRT, three-dimensional conformal radiation therapy; IMRT, intensitymodulated radiation therapy; ISH, International Society of Hypertension; NOS, not otherwise specified; SCRT, sequential CRT; WHO-PS, WHOperformance score.

(cardiopulmonary resuscitation). Of all patients, 45 $(9.8 \%)$ developed more than one event. Ninety-three $(62 \%)$ events occurred in the first year after diagnosis. The incidence of cardiac events after 18 and 24 months was respectively $23.3 \%$ (107 events) and 26\% (120 
Table 2 Survival and new cardiac events $(n=460)$

\begin{tabular}{lll}
\hline & $\mathbf{N}$ & $\%$ \\
\hline 5-year survival & 118 & 25.7
\end{tabular}

New cardiac events $<5$ years, CTCAE $\geq 2$ *

\begin{tabular}{llr} 
Yes & 150 & 32.6 \\
$\begin{array}{l}\text { Type cardiac event } \\
\text { Arrhythmia }\end{array}$ & 68 & 14.7 \\
$\begin{array}{l}\text { Symptomatic coronary artery } \\
\text { disease }\end{array}$ & 30 & 6.5 \\
Pericardial disease & 13 & \\
Heart failure & 33 & 2.8 \\
Cardiomyopathy NOS $†$ & 6 & 7.2 \\
\hline
\end{tabular}

Overall time to event, months (median, 9 (0-60) range)

$>1$ cardiac event

45

*The severity of the event was graded using the CTCAE V.4.0. †Cardiomyopathy NOS: cardiac resuscitation and cardiomyopathy NOS.

CTCAE, common terminology criteria for adverse events; NOS, not otherwise specified.

events). The median time to worst cardiac event was 9 months (mean 13.6; SD 14.5; range 0-60 months). There was no significant difference in the number of cardiac events between patients treated with cCRT or sCRT. Details on all cardiac events are shown in table 2. The overall cumulative incidence of a cardiac event corrected for the competing risk of death is shown in figure 2.

\section{Clinical risk factors}

On univariate analysis, male gender, age $\geq 70$, high WHO-PS $\geq 2$, high CCI score of 7-9, use of statins which reflex hypercholesterolaemia and pre-existent cardiac comorbidity were significantly associated with the development of a new cardiac event within 5 years. However, on multivariate analysis only pre-existent cardiac comorbidity (HR $1.96 ; 95 \%$ CI 1.29 to $2.98 ; \mathrm{p}<0.01$ ) and WHO-PS $\geq 2$ (HR 2.71; 95\% CI 1.33 to 5.52; $<<0.01$ ) were independent significant predictors for a cardiac event (table 3 ).

\section{Subgroup analysis}

Pre-existent cardiac comorbidity

In the subgroup of patients with a cardiac history $(\mathrm{n}=138$, $30 \%), 61(44.2 \%)$ patients developed a new cardiac event during follow-up. On univariate analysis, WHO-PS $\geq 2$ and cisplatin-based treatment were significantly associated with the development of a new cardiac event. On multivariate analysis both factors remained significantly risk factors (HR 3.77; 95\% CI 1.12 to $12.70 ; \mathrm{p}=0.032$ and HR 2.85; $95 \%$ CI 1.36 to 5.98; $\mathrm{p}=0.006$, respectively; table 4$)$. The median time to worst cardiac event was 7 months (mean $12.3 \pm 12.7$ months). The incidence of cardiac events in this group after 12, 18 and 24 months was respectively $43(31.2 \%), 46(33.3 \%)$ and $51(37 \%)$.

\section{No pre-existent cardiac comorbidity}

The majority of patients did not have pre-existent cardiac comorbidity $(\mathrm{n}=322,70 \%)$. Of these patients, $33 \%$ had an elevated risk $(>10 \%)$ to develop a serious cardiac event according to the WHO/ISH risk chart. Eighty-nine $(27.6 \%)$ patients developed a cardiac event. Nevertheless, univariate analysis did not identify a high WHO/ ISH score as a significant predictor for a cardiac event. No other clinical factor was significantly associated with the development of a cardiac event. The median time

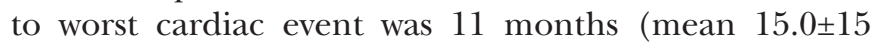
months). The incidence of cardiac events after 12, 18 and

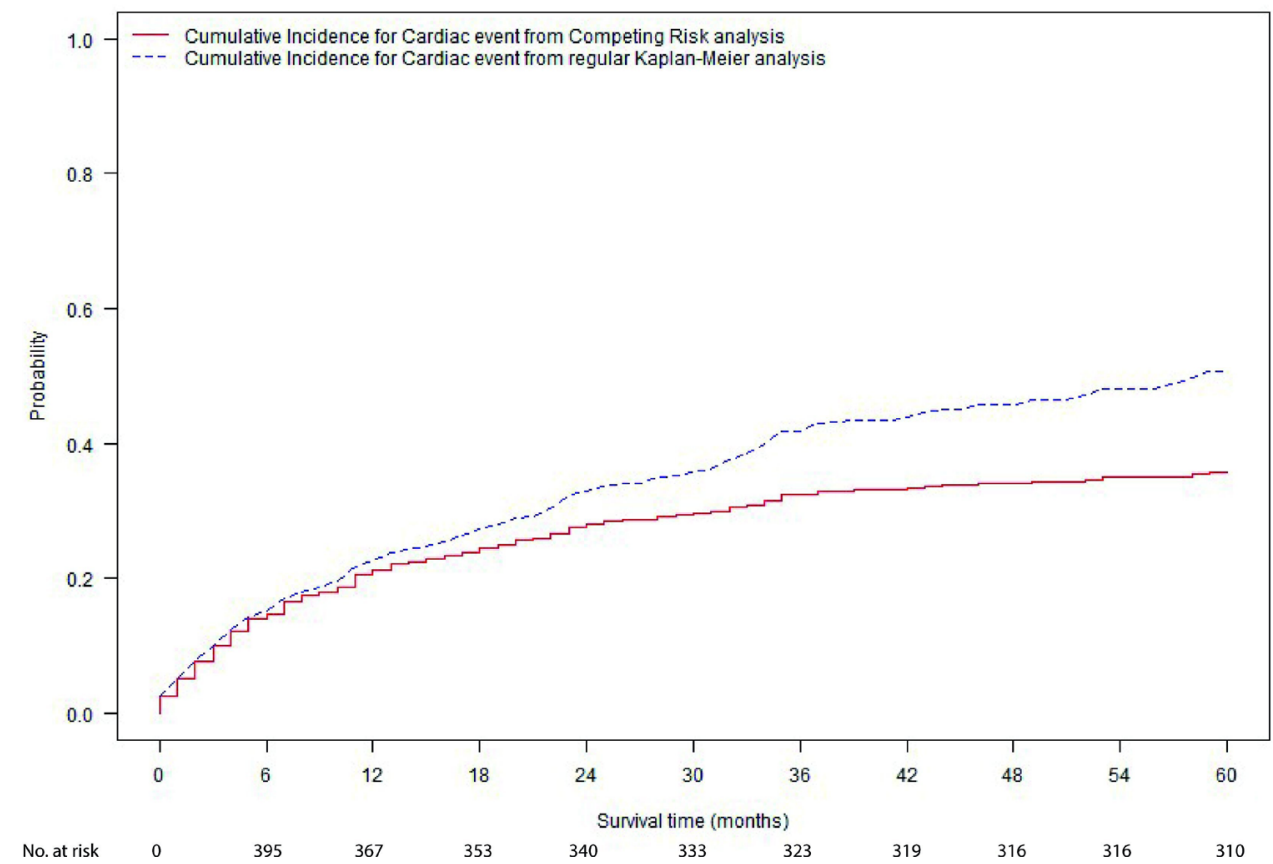

Figure 2 Cumulative incidence corrected for the competing risk of death. 
Table 3 Univariate and multivariate analysis $(n=460)$

\begin{tabular}{|c|c|c|c|c|c|c|c|c|c|}
\hline \multirow[b]{3}{*}{ Covariate } & \multicolumn{5}{|c|}{ Univariate analysis } & \multicolumn{4}{|c|}{ Multivariate analysis } \\
\hline & \multirow[b]{2}{*}{ HR } & \multicolumn{2}{|l|}{$95 \% \mathrm{Cl}$} & \multirow[b]{2}{*}{$P$ value } & \multirow[b]{2}{*}{$\mathbf{N}$} & \multirow[b]{2}{*}{ HR } & \multicolumn{2}{|l|}{$95 \% \mathrm{Cl}$} & \multirow[b]{2}{*}{$P$ value } \\
\hline & & Lower & Upper & & & & Lower & Upper & \\
\hline Age ( $\geq 70$ year) & 1.54 & 1.03 & 2.30 & 0.04 & 165 & & & & \\
\hline WHO-PS $(\geq 2)^{*}$ & 3.03 & 1.50 & 6.10 & 0.04 & 35 & 2.71 & 1.33 & 5.52 & $<0.01$ \\
\hline High (7-9) & 2.50 & 1.39 & 4.0 & $<0.01$ & 71 & & & & \\
\hline Pre-existing cardiac comorbidity, yes & 2.07 & 1.37 & 3.14 & $<0.01$ & 138 & 1.96 & 1.29 & 2.98 & $<0.01$ \\
\hline Statin use, yes & 1.61 & 1.04 & 2.48 & 0.03 & 118 & & & & \\
\hline \multicolumn{10}{|c|}{ WHO 10-year risk of serious cardiac event $\ddagger$} \\
\hline$>10 \%$ & 0.95 & 0.63 & 1.44 & 0.81 & 177 & & & & \\
\hline
\end{tabular}

*WHO-PS: quantifies general well-being and activities of daily life of patients with cancer.

$+\mathrm{CCl}$ : prediction of the 10-year survival in patients with multiple comorbidities.

‡WHO/ISH risk prediction score: indicates 10 -year risk of a fatal or non-fatal major cardiovascular event according to age, sex, blood pressure, smoking status and diabetes mellitus status.

$\mathrm{CCl}$, Charlson comorbidity index; WHO/ISH, WHO/International Society of Hypertension; WHO-PS, WHO-performance score.

24 months in this group was respectively $50(15.5 \%), 61$ $(18.9 \%)$ and $69(21.4 \%)$.

\section{Survival}

All patients were followed for at least 5 years or until death. The 5 -year survival rate was $25.7 \%$ with a median OS of 23 months (95\% CI 20.5 to 25.5). In univariate cox regression analysis age $\geq 70$ years $(\mathrm{HR}=1.71 ; 95 \% \mathrm{CI}$ 1.08 to $2.71, \mathrm{p}=0.02)$ and WHO-PS $\geq 2$ (HR=3.96; $95 \%$ CI 1.19 to $13.17, \mathrm{p}=0.025$ ) were significantly associated with survival. The development of a cardiac event was not of significant influence. Twenty-three $(5 \%)$ patients died of a fatal cardiac event. However, this number could be an underestimation because in $78(17 \%)$ of the patients the precise cause of death was unknown.

\section{DISCUSSION}

To our knowledge, this study is the first to analyse the 5-year follow-up of cardiac comorbidity and cardiac events in patients with stage III NSCLC treated with CRT in routine clinical practice, taking into account cardiac dose constraints. Our results show that cardiac events are a highly prevalent, under-reported problem. This renders our dataset relevant to all physicians confronted with patients with NSCLC post CRT, especially GPs as they are usually the first point of contact for patients. Of all patients, $150(32.6 \%)$ developed a new cardiac event with a median time to worst cardiac event of 9 months (mean 13.6; SD 14.5; range 0-60 months). The most common cardiac events were arrhythmia (14.6\%), heart failure $(7.6 \%)$ and symptomatic coronary artery disease $(6.8 \%)$. Pre-existent cardiac comorbidity and WHO-PS $\geq 2$ were significantly associated for developing a new cardiac event. Our results show that $62 \%$ of all cardiac events develop within the first 12 months after diagnosis. In patients with pre-existent cardiac comorbidity, WHO PS $\geq 2$ and treatment with cisplatin-based therapy during CRT was significantly associated with the development of a cardiac event. In patients without a pre-existent cardiac history, high WHO/ISH score was not significantly associated with the development of a cardiac event.

Table 4 Univariate and multivariate analysis of pre-existing cardiac comorbidity $(n=138)$

\begin{tabular}{|c|c|c|c|c|c|c|c|c|c|}
\hline \multirow[b]{3}{*}{ Covariate } & \multicolumn{5}{|c|}{ Univariate analysis } & \multicolumn{4}{|c|}{ Multivariate analysis } \\
\hline & \multirow[b]{2}{*}{ HR } & \multicolumn{2}{|c|}{$95 \% \mathbf{C l}$} & \multirow[b]{2}{*}{$P$ value } & \multirow[b]{2}{*}{$\mathbf{N}$} & \multirow[b]{2}{*}{ HR } & \multicolumn{2}{|c|}{$95 \% \mathbf{C l}$} & \multirow[b]{2}{*}{$P$ value } \\
\hline & & Lower & Upper & & & & Lower & Upper & \\
\hline \multicolumn{10}{|c|}{ Type of platinum-based therapy, first line } \\
\hline Cisplatin & 3.30 & 1.60 & 6.80 & $<0.01$ & 73 & 2.80 & 1.40 & 5.90 & $<0.01$ \\
\hline
\end{tabular}

*WHO-PS: quantifies general well-being and activities of daily life ofpatients with cancer.

WHO-PS, WHO-performance score. 
To reflect daily clinical practice, we chose to include all cardiac events with a CTCAE score of $\geq 2$ to investigate the mild to severe impact and incidence of cardiac events. Our results show that most cardiac events develop in the first year after diagnosis. Comparable to previous studies, arrhythmias, which often present with dyspnoea and decreased exercise tolerance, were the most frequently observed cardiac events in the first year after diagnosis. ${ }^{13}$ The incidence of arrhythmias in the current study population is remarkably higher than expected in this age group based on a Dutch population based prospective cohort study. ${ }^{17}$ The 5 -year cumulative risk for developing atrium fibrillation was $2.8 \%$ in men and $2.0 \%$ in women at the age of 65 compared with an incidence of $14.7 \%$ in the current study. The incidence of cardiac events described in the current study is comparable with previous published numbers by Billiet $e t a l .{ }^{18}$ Here, stage III NSCLC had undergone surgical resection and if necessary, were treated with postoperative radiotherapy. The incidence of different cardiac events were comparable between the two patient groups and the results of the current study, emphasising that the development of cardiac events is associated with individual risk factors and not only correlated with specific treatment.

Seventy percent of the study population had a negative history for cardiac comorbidity. Nevertheless, $27.6 \%$ of these patients developed a cardiac event. In this group, we could not identify a risk factor for developing a cardiac event. Similar to other studies, no significant association between the WHO/ISH score, which is often used to assess cardiovascular risk, and the development of a cardiac event was found. ${ }^{13}$

The OS was not significantly influenced by the development of cardiac events in this cohort. However, prediction models for survival in lung cancer showed that a large lung tumour, active smoking during therapy and high radiation dose to the heart are predictive for mortality. ${ }^{19}$

The main strength of our study comes from a large, multicentre, well-defined, group of consecutive patients with stage III NSCLC, who were treated according to the standard clinical care. All patients' records have been systematically reviewed based on a predetermined search strategy. Therefore, we believe that our results are representative for daily clinical practice. Because of the retrospective analysis of cardiac events, we cannot rule out that some cardiac events with CTCAE score $\geq 2$ were missed. Therefore, our results could be an underestimation of the total amounts of cardiac events in our population. Previous studies have identified a higher mean heart dose as a significant prognostic factor for cardiac events. ${ }^{12} 132021$ However, a detailed analysis of the dosevolume parameters of radiotherapy in relation to cardiac events is beyond the scope of this work and internationally agreed dose constraints were taken into account. Because of increased awareness of the cardiac side effects, more emphasis has emerged in cardiac sparing radiotherapy techniques, including IMRT, proton therapy and
MRI-guided radiotherapy. ${ }^{22}$ These have resulted in new guidelines, which may further decrease toxicity. ${ }^{23}$

In view of the high prevalence of heart disease in this population, we suggest that patients at risk for cardiovascular complications, should be seen by a cardiologist prior to CRT for optimalisation of their cardiac condition. In addition, both the treating clinical physicians and the GP should take cardiac comorbidity as a serious possible explanation for dyspnoea after treatment with CRT. So, patients with unexplained complaints during or post treatment should be referred for screening of cardiovascular disease, with emphasis on cardiovascular events with high incidence as described in this study such as heart failure or arrhythmias. Nevertheless, future research has to reveal whether screening and treatment for cardiac comorbidity before start of treatment will diminish the incidence of mild to severe cardiac events in patients with stage III NSCLC.

\section{Author affiliations}

${ }^{1}$ Departement of Respiratory Medicine, NUTRIM School of Nutrition and Translational Research in Metabolism, Maastricht Universitair Medisch Centrum+, Maastricht, the Netherlands

${ }^{2}$ Department of Radiation Oncology, GROW School for Oncology and Developmental Biology, MAASTRO, Maastricht, the Netherlands

${ }^{3}$ Department of Radiation Oncology, MAASTR0, Maastricht, the Netherlands

${ }^{4}$ Department of Cardiology, Zuyderland Medical Centre Heerlen, Heerlen, the Netherlands

${ }^{5}$ Department of Respiratory Medicine, Zuyderland Medical Centre Heerlen, Heerlen, the Netherlands

${ }^{6}$ Department of Respiratory Medicine, GROW School for Oncology and

Developmental Biology, Maastricht Universitair Medisch Centrum+, Maastricht, the Netherlands

${ }^{7}$ General Practitioner, focus on Cardio-Vascular Risk Management, DOH Zorggroep, Eindhoven, the Netherlands

${ }^{8}$ NUTRIM School of Nutrition and Translational Research in Metabolism, Maastricht University, Maastricht, the Netherlands

${ }^{9}$ GROW School for Oncology and Developmental Biology, Maastricht University, Maastricht, the Netherlands

${ }^{10}$ Department of Respiratory Medicine, Erasmus Medical Center, Rotterdam, the Netherlands

Contributors JD designed the research, conducted research, analysed the data and wrote the paper. DDR, BK, GB and LH provided the essential materials. $\mathrm{RH}$ helped in statistical analysis. EH provided the input for the manuscript. AS designed the research, and had primary responsibility for final content. AMCD provided the essential material, designed the research and had primary responsibility for final content.

Funding The authors have not declared a specific grant for this research from any funding agency in the public, commercial or not-for-profit sectors.

Competing interests DDR reports personal fees from advisory board BristolMyers-Squibb, advisory board Roche/ Genentech, advisory board Merck/ Pfizer, advisory board Celgene, advisory board AstraZeneca, advisory board NOXXON, advisory board Mologen, outside the submitted work. LH reports other from Boehringer Ingelheim, Roche and AstraZeneca, and grants from Roche, Boehringer Ingelheim, personal fees from Quadia, outside the submitted work. AMCD reports personal fees from advisory board BMS, advisory board MSD, advisory board Roche, advisory board Eli Lilly, advisory board Takeda, advisory board Pfizer, advisory board Boehringer Ingelheim, outside the submitted work. JD, RH, BK, GB, EH, AS: none declared

Patient consent for publication Not required.

Provenance and peer review Not commissioned; externally peer reviewed.

Data availability statement Data are available upon reasonable request. The individual participant data that underlie the results reported in this article will be 
available (after deidentification) upon reasonable request. Data will be available immediately following publication. Data requests can be sent to a.dingemans@ erasmusmc.nl.

Open access This is an open access article distributed in accordance with the Creative Commons Attribution Non Commercial (CC BY-NC 4.0) license, which permits others to distribute, remix, adapt, build upon this work non-commercially, and license their derivative works on different terms, provided the original work is properly cited, appropriate credit is given, any changes made indicated, and the use is non-commercial. See: http://creativecommons.org/licenses/by-nc/4.0/.

ORCID iD

Juliette Degens http://orcid.org/0000-0003-0279-9656

\section{REFERENCES}

1 Lung cancer statistics. World cancer research fund.

2 Barta JA, Powell CA, Wisnivesky JP. Global epidemiology of lung cancer. Ann Glob Health 2019;85

3 Walters S, Maringe C, Coleman MP, et al. Lung cancer survival and stage at diagnosis in Australia, Canada, Denmark, Norway, Sweden and the UK: a population-based study, 2004-2007. Thorax 2013;68:551-64.

4 Goldstraw P, Chansky K, Crowley J, et al. The IASLC lung cancer staging project: proposals for revision of the TNM stage groupings in the forthcoming (eighth) edition of the TNM classification for lung cancer. J Thorac Oncol 2016;11:39-51.

5 Postmus PE, Kerr KM, Oudkerk M, et al. Early and locally advanced non-small-cell lung cancer (NSCLC): ESMO clinical practice guidelines for diagnosis, treatment and follow-up. Ann Oncol 2017;28:iv1-21.

6 Yoon SM, Shaikh T, Hallman M. Therapeutic management options for stage III non-small cell lung cancer. World J Clin Oncol 2017;8:1-20.

7 Schild SE, Vokes EE. Pathways to improving combined modality therapy for stage III nonsmall-cell lung cancer. Ann Oncol 2016;27:590-9.

8 Antonia SJ, Villegas A, Daniel D, et al. Durvalumab after chemoradiotherapy in stage III non-small-cell lung cancer. $N$ Engl J Med 2017;377:1919-29.

9 Gray JE, Villegas A, Daniel D, et al. Three-year overall survival with Durvalumab after chemoradiotherapy in stage III NSCLC-update from Pacific. J Thorac Oncol 2020;15:288-93.

10 Antonia SJ, Villegas A, Daniel D, et al. Overall survival with Durvalumab after chemoradiotherapy in stage III NSCLC. $N$ Engl J Med 2018;379:2342-50.
11 Eberhardt WEE, De Ruysscher D, Weder W, et al. 2nd ESMO consensus conference in lung cancer: locally advanced stage III nonsmall-cell lung cancer. Ann Oncol 2015;26:1573-88.

12 Dess RT, Sun Y, Matuszak MM, et al. Cardiac events after radiation therapy: combined analysis of prospective multicenter trials for locally advanced non-small-cell lung cancer. J Clin Oncol 2017;35:1395-402.

13 Wang K, Eblan MJ, Deal AM, et al. Cardiac toxicity after radiotherapy for stage III non-small-cell lung cancer: pooled analysis of dose-escalation trials delivering 70 to 90 Gy. J Clin Oncol 2017;35:1387-94.

14 Wang K, Pearlstein KA, Patchett ND, et al. Heart dosimetric analysis of three types of cardiac toxicity in patients treated on doseescalation trials for stage III non-small-cell lung cancer. Radiother Oncol 2017;125:293-300.

15 Atkins KM, Rawal B, Chaunzwa TL, et al. Cardiac radiation dose, cardiac disease, and mortality in patients with lung cancer. $J$ Am Coll Cardiol 2019;73:2976-87.

16 Fleming C, Cagney DN, O’Keeffe S, et al. Normal tissue considerations and dose-volume constraints in the moderately hypofractionated treatment of non-small cell lung cancer. Radiother Oncol 2016;119:423-31.

17 Heeringa J, van der Kuip DAM, Hofman A, et al. Prevalence, incidence and lifetime risk of atrial fibrillation: the Rotterdam study. Eur Heart J 2006;27:949-53.

18 Billiet C, Peeters S, Decaluwé $\mathrm{H}$, et al. Outcome after port in ypN2 or R1/R2 versus no port in ypN0 stage III-N2 NSCLC after induction chemotherapy and resection. J Thorac Oncol 2016;11:1940-53.

19 Defraene G, Dankers FJWM, Price G, et al. Multifactorial risk factors for mortality after chemotherapy and radiotherapy for non-small cell lung cancer. Radiother Oncol 2019;S0167-8140:33078-6.

20 Stam B, van der Bijl E, van Diessen J, et al. Heart dose associated with overall survival in locally advanced NSCLC patients treated with hypofractionated chemoradiotherapy. Radiother Oncol 2017;125:62-5

21 Speirs CK, DeWees TA, Rehman S, et al. Heart dose is an independent dosimetric predictor of overall survival in locally advanced non-small cell lung cancer. $J$ Thorac Oncol 2017;12:293-301.

22 Chun SG, Hu C, Choy H, et al. Impact of intensity-modulated radiation therapy technique for locally advanced non-small-cell lung cancer: a secondary analysis of the NRG oncology RTOG 0617 randomized clinical trial. J Clin Oncol 2017;35:56-62.

23 De Ruysscher D, Faivre-Finn C, Moeller D, et al. European organization for research and treatment of cancer (EORTC) recommendations for planning and delivery of high-dose, high precision radiotherapy for lung cancer. Radiother Oncol 2017;124:1-10. 